TSH response to TRF was within the normal range while the patient was taking $60 \mu \mathrm{g}$ L-triiodothyronine daily suggesting adequate replacement therapy.

\section{Acknowledgments}

We are grateful to Dr A. Stockell Hartree and Dr W. Butt, to the Medical Research Council, and the National Pituitary Agency, Endocrine Section, National Institute of Arthritis and Metabolic Diseases, U.S.A., for providing reagents for the immunoassay procedures.

\section{References}

Bellini, M.A. \& Neves, I. (1956) The skull in childhood myxoedema: its Roentgen appearance. American Journal Roentgenology, 76, 495.

Bocian, M., Krmpotic, E., Szego, K. \& Rosenthal, R. (1971) Somatic stigmata of Turner's syndrome in a patient with 46XXq-. Journal of Medical Genetics, 8, 358.

Brauman, H., Smets, P. \& Corvilain, J. (1973) Growth hormone response to hypoglycaemia in myxoedema. Journal of Clinical Endocrinology and Metabolism, 36, 1162.

Caughey, J.E. \& Lester, M.J. (1961) Hypothyroidism and pituitary tumours. New Zealand Medical Journal, 60, 486.

Evered, D.C., Ormston. B.J., Smith, P.A., Hall, R. \& BIRD, T. (1973) Grades of hypothyroidism. British Medical Journal, 1, 657.

Greulich, W.W. \& Pyle, S.I. (1950) In: Radiographic Atlas of Skeletal Development of the Hand and Wrist. Stanford University Press.

Hecht, F., Jones, D.L., Delay, M. \& Klevit, H. (1970) XqTurner's syndrome: reconsideration of hypothesis that $\mathrm{Xp}$ - causes somatic features of Turner's syndrome. Journal of Medical Genetics, 7, 14.
Herlant, M.M., Linquette, E., Laine, P., Fossati, J.P., MAY, J.T. \& LefebVRE, J. (1966) Adénome hypophysaire à cellules thyréotropes avec syndrome aménorrhée-galactorrhée chez une malade porteuse d'un myxoédème congénital par éctopie thyroïdienne. Annales d'Endocrinologie, 27, 181.

Iwatsubo, H., Omori, K., OKada, Y., Fukuchi, K., Miyai, K., Abe, H. \& Kumahara, Y. (1967) Human growth hormone secretion in primary hypothyroidism before and after treatment. Journal of Clinical Endocrinology and Metabolism, 27, 1751.

LANCET Leading Article (1973) The empty sella. Lancet, i, 925.

LipPe, B.M. \& Crandall, B.F. (1973) Turner's syndrome with partial deletion of the $\mathrm{X}$ chromosome long arm. American Journal of Diseases of Children, 126, 2.

MelNyK, C.S. \& Greer, M.A. (1965) Functional pituitary tumour in an adult possibly secondary to long-standing myxoedema. Journal of Clinical Endocrinology and Metabolism, 25, 761 .

Neelon, F.A., Goree, J.A. \& Lebovitz, H.F. (1973) The primary empty sella: clinical and radiographic characteristics and endocrine function. Medicine, 52, 73.

Russfield, A.B. (1958) Hypophyseal changes in hypothyroidism induced by radioactive iodine in man. A.M.A. Archives of Pathology, 66, 79.

SEABright, M. (1971) A rapid banding technique for human chromosomes. Lancet, ii, 971.

Tunbridge, W.M.G., Marshall, J.C. \& Burke, C.W. (1973) Primary hypothyroidism presenting as pituitary failure. British Medical Journal, i, 153.

VAN WyCK, J.J. \& Grumbach, M.M. (1960) Syndrome of precocious menstruation and galactorrhoea in juvenile hypothyroidism: an example of hormonal overlap in pituitary feedback. Journal of Pediatrics, 57, 614.

\title{
Problems in the management of mediastinal tumours
}

\author{
R. C. LALlemand* \\ M.B., F.R.C.S.
}

J. R. W. KEATES

M.B., F.R.C.S.

\section{Departments of Surgery and Thoracic Surgery, Guy's Hospital, London}

\section{Summary}

Five cases of anterior mediastinal tumour are presented. Two cases were asymptomatic, being discovered by routine chest radiography. The remainder presented with dyspnoea, dysphagia and a sinus over the manubrium.

Each case provided a lesson in the management of the mediastinal mass. Pathologies included haemangioma, teratoma, secondary carcinoma from the kidney and a malignant thymoma which caused cardiac tamponade.

Features of interest in the presentation, treatment and pathology are discussed.

* Present address: Frimley Park Hospital, Frimley, Surrey GU16 5UJ.
It is concluded that a full investigation of mediastinal swellings is needed before mediastinoscopy is performed; that incision of swellings in the base of the neck should be avoided; and it is suggested that the management of asymptomatic mediastinal haemangioma in adults may be expectant.

\section{Introduction}

Mediastinal tumours are not uncommon and several large series have been documented (Blades, 1946; Boyd and Midell, 1968; Brewer and Dolley, 1949; Heuer and Andrus, 1940; Wychulis et al., 1971). Presentation is normally by symptoms due to involvement or pressure on the trachea and neighbouring structures. In no series has there been a large 
proportion of asymptomatic tumours, and most dismiss the presentation of metastases in the mediastinum as being from the usual primary source such as lung, breast, oesophagus, or as being part of a lymphomatous process.

Five cases are described, three of unusual tumour and two where presentation and progress were unusual. Each case has provided a lesson in the management of mediastinal tumour.

\section{Case histories}

\section{Teratoma}

Case 1. 22-year-old male. Discharging sinus over the manubrium for 1 year. The patient had noticed a lump in the neck 1 year previously which had been incised at another hospital. Since then he had had recurrent inflammatory swellings above the sternum which had been surgically drained. On examination there was a sinus just above and to the left of the manubrium which was surrounded by granulation tissue and discharged foul-smelling pus which grew Staphylococcus aureus. X-rays had shown a soft tissue shadow behind the manubrium with osteomyelitis of the sternum (Fig. 1).

The anterior mediastinum was explored with resection of the manubrium, medial one quarter of the clavicles, and the first and second costal cartilages. During the exploration it became apparent from the appearance of skin and hairs under the sternum that the primary lesion was a teratoma. It was not possible to determine whether involvement of the thy-

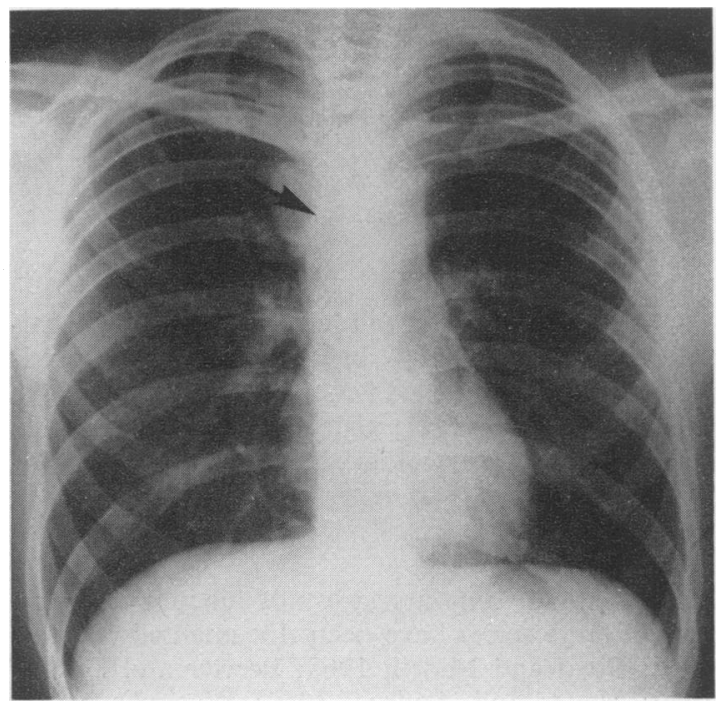

FIG. 1. Case 1. Chest $X$-ray showing mediastinal swelling before incision of swelling in suprasternal notch. mus, anterior segment of the right upper lobe, or the left innominate vein, was inflammatory or neoplastic; accordingly these structures were excised en bloc. Simple closure of the skin was performed. Recovery was uneventful. Plastic repair of the upper chest with a steel mesh was performed 3 years later. He remains in excellent health.

Histology showed a benign cystic teratoma with non-keratinizing squamous, mucus-secreting and respiratory epithelia. Sweat glands were seen. There was cavernous erectile tissue in places with reactive hyperplasia in lymphatic tissue.

This unusual presentation with a history of recurrent sinuses in the base of the neck led to the mistaken initial diagnosis of sternal osteomyelitis. At operation the manubrium was resected as there was radiographic evidence of its involvement. Rusby noted in his comprehensive review (Rusby, 1944) that a bulging in the root of the neck or around the sternum, especially if accompanied by signs of inflammation, was a frequent presenting sign of teratoma in his collection of cases.

\section{Two cases of metastatic hypernephroma}

Case 2. 45-year-old male. Asymptomatic mediastinal mass. Following 'gastric influenza' in June 1970 routine chest X-ray showed a right paratracheal mass (Fig. 2). Inclined frontal plane tomography (Greenwell and Wright, 1965) suggested mediastinal lymph gland enlargement (Fig. 3). Blood picture and ESR normal. Mediastinoscopy and biopsy showed

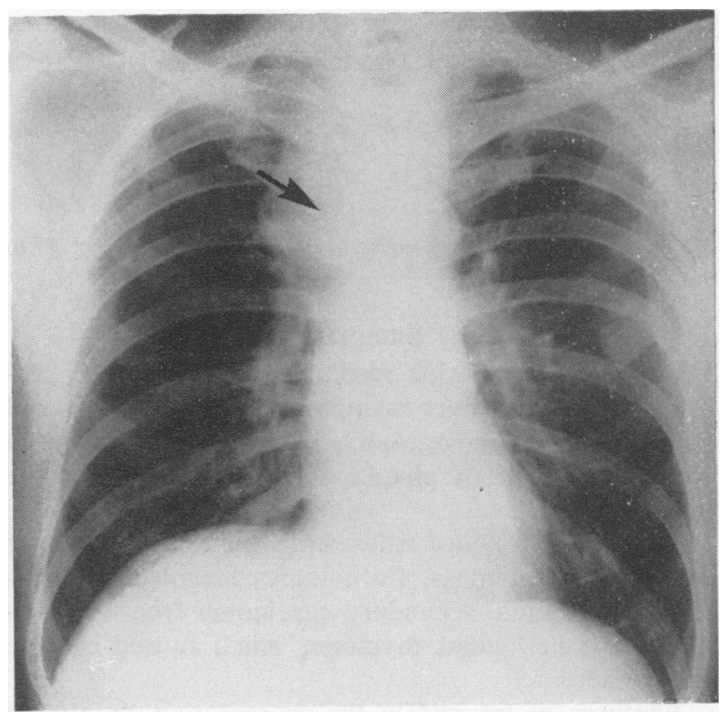

FIG. 2. Case 2. Chest X-ray showing right-sided mediastinal swelling. The deposit in the 7th rib is not seen but was apparent on chest X-ray taken 6 weeks later. 
lymph gland invaded by a clear-celled carcinoma with vesicular cytoplasm and pyknotic nuclei; mitoses scanty. During this admission erosion of the lower border of the left 7 th rib was noted on chest X-ray. Intravenous pyelography showed a tumour deforming upper and middle calyces of the left kidney. The upper ureter was displaced laterally by a para-aortic mass. Before nephrectomy was performed

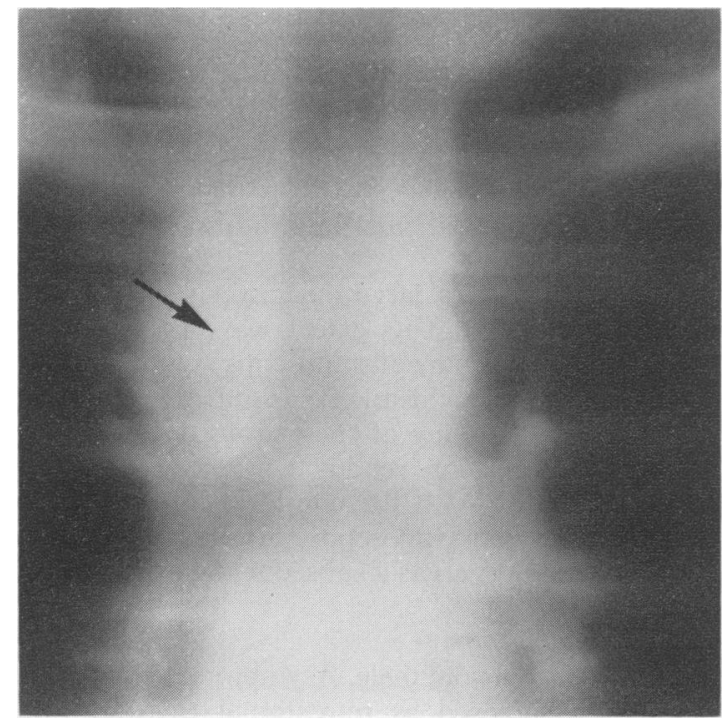

Fig. 3. Case 2. Inclined frontal plane tomogram showing right paratracheal glandular enlargement in addition to anterior mediastinal glands. There is also some filling of the angle between the aorta and pulmonary trunk suggesting left paratracheal glandular enlargement which narrowed the left main bronchus.

in August there was a palpable mass under the left costal margin. Histology showed a well differentiated hypernephroma with clear cells at its periphery and invasion of the renal vein. Enlarged paraaortic lymph glands contained metastases.

Treated with cyclophosphamide $50 \mathrm{mg}$ b.d. and medroxyprogesterone $100 \mathrm{mg}$ t.d.s. Review in November 1971 revealed anaemia $(10.8 \mathrm{~g} \%$ of haemoglobin) and enlargement of the mediastinal mass from 8 to $9 \mathrm{~cm}$. The lesion in the left 7 th rib had enlarged from 3 to $14 \mathrm{~cm}$ and two ribs were now invaded. However, he remained symptom free until July 1972, 2 years after presentation, when he was admitted with bronchopneumonia and died. There were by now bilateral supraclavicular metastases, and further enlargement of masses in the ribs had occurred.

The possibility that the mediastinal tumour was a metastasis was missed until the deposit was noted in the left rib. In retrospect it was just visible on the first chest film. At no time was there evidence of pulmonary deposit to suggest that the mediastinal lymphadenopathy represented tertiary spread.

Case 3. 62-year-old male. Mediastinal mass invading trachea and oesophagus. In January 1971 presented with dysphagia and a cough. X-rays showed a posterior mediastinal mass compressing both oesophagus and tracheal bifurcation (Fig. 4). Lung fields were clear. Twenty years previously a left nephrectomy had been performed for hypernephroma. Histological examination had shown penetration of the capsule and invasion of veins. Regular follow-up, without chest X-rays, had shown no evidence of recurrence.

At thoracotomy a nodular mass below the tracheal bifurcation was found adherent to both bronchi, oesophagus and aorta. Biopsy showed lymphatic tissue invaded by a poorly differentiated metastatic clear-celled carcinoma of renal origin and similar to the renal primary tumour removed in 1951. Owing to invasion of surrounding structures removal was

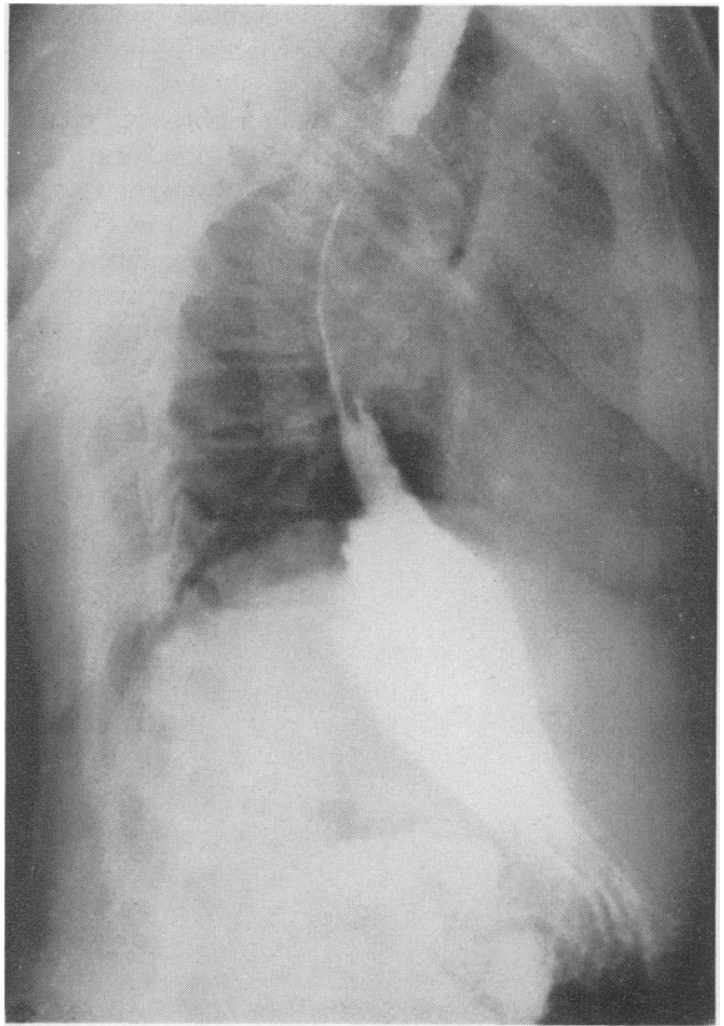

Fig. 4. Case 3. Barium swallow lateral view showing outline of mediastinal mass invading oesophagus and compressing trachea. 
incomplete and a full course of radiotherapy was given to the mediastinum. The patient became symptom free and the mass was no longer visible on X-ray. However, within 6 months the initial symptoms had returned and he was given medroxyprogesterone $100 \mathrm{mg}$ t.d.s. There was no response and so this was followed by a course of quadruple chemotherapy (5-fluorouracil, methotrexate, vinblastine and cyclophosphamide). There was again no response and the left lung collapsed progressively owing to bronchial obstruction. He finally died in August 1972, 20 months after presenting with his mediastinal metastasis but 21 years after the nephrectomy for hypernephroma. Chest X-ray just before he died still showed no evidence of pulmonary deposits.

It will be noted that the renal veins had been invaded by tumour at the time of nephrectomy. It is probable that this mediastinal solitary glandular deposit lay dormant for 20 years after nephrectomy for no other metastases were found even in the lungs.

\section{Thymoma}

Case 4. 32-year-old male. Anterior mediastinal mass involving pericardium. Presented on 12 April 1973 with a 4-week history of progressive breathlessness. On examination he was grossly dyspnoeic with engorged neck veins and signs of a right-sided pleural effusion. X-rays on admission confirmed the rightsided effusion and in addition showed a widened superior mediastinum and cardiac shadow (Fig. 5). Removal of 1.21 of pleural fluid produced only transitory relief and no cytological information. A diagnosis of malignant mediastinal tumour, possibly

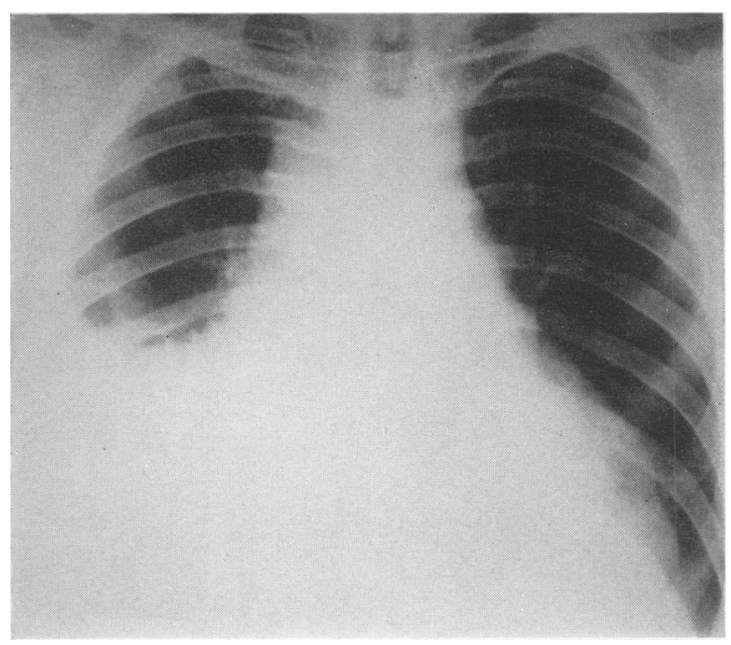

Fig. 5. Case 4. Chest X-ray showing pleural effusion and cardiomegaly with a left hilar mass. reticulosis, was made and a histological diagnosis sought by mediastinoscopy before instigating treatment. Under general anaesthetic mediastinoscopy revealed a large rubbery tumour; frozen section showed malignant thymoma. Following this procedure the patient suffered respiratory embarrassment and had to be ventilated. Cardiac tamponade was also diagnosed on account of raised right atrial pressure and pulsus paradoxus. Attempts at aspiration of the pericardial cavity were unsuccessful. He deteriorated quickly and died the following day. At post mortem a very large lobulated tumour was present in the anterior mediastinum measuring approximately $25 \mathrm{~cm} \times 25 \mathrm{~cm} \times 10 \mathrm{~cm}$. It was infiltrating the pericardium and almost completely enveloping the heart.

Histology showed an infiltrating lymphocytic thymoma.

The presence of a large mediastinal tumour had been established, but its extent was not sought by tomography before mediastinoscopy was performed to obtain tissue for histology. Insufficient attention was paid to the failure of chest aspiration to relieve dyspnoea. Persistent venous engorgement should have been seen. With the consideration of cardiac tamponade, mediastinoscopy would have been deemed as dangerous as it subsequently proved to be.

\section{Vascular hamartoma}

Case 5. 48-year-old male. Asymptomatic mediastinal mass diagnosed as retrosternal thyroid. First seen after a minor injury at work. A routine chest $\mathrm{X}$-ray showed a left upper mediastinal shadow (Fig. 6). Referred as a case of retrosternal goitre, he was admitted for further investigation and exploration of the tumour. He had no symptoms, but on direct questioning admitted to being aware of a lump coming up on the left side of his neck for the past 6 months. The only abnormal findings were that the trachea was deviated to the right by a soft mass felt on the left side of the neck which became more prominent on coughing and swallowing. The lower limit of this mass could not be felt. Thyroid function studies and scan were normal. Barium swallow showed displacement of the upper oesophagus to the right by a tumour. A clinical diagnosis of retrosternal plunging goitre was made.

Exploration of the tumour was made through a collar incision. The left lobe of the thyroid was normal, but below it was a tumour mass which in some places was filled with blood and in others felt hard. In order to define the extent of the tumour the skin incision was extended to include a median sternotomy. It was found that the tumour mass extended inferiorly as far as the hilum of the lung, medially it covered the arch of the aorta and pulmonary trunk, laterally it had lifted the phrenic 


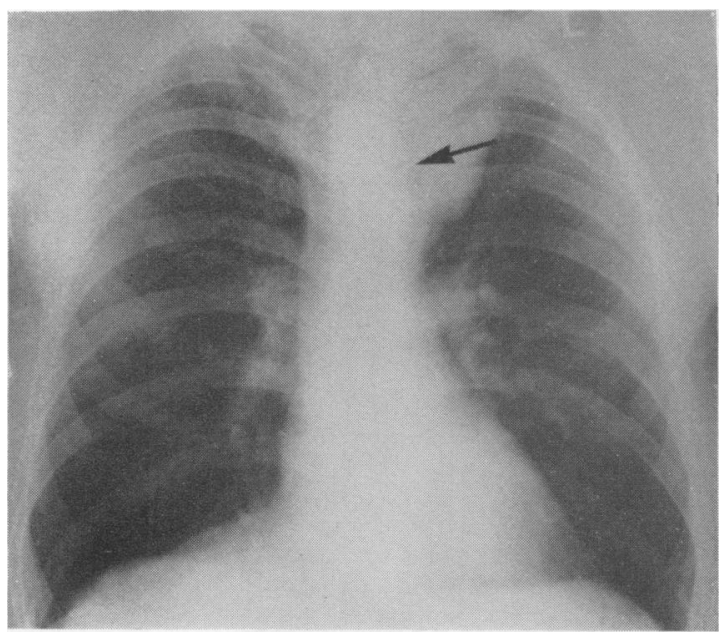

FIG. 6. Case 5. Chest X-ray showing anterior mediastinal swelling. There is deviation of the trachea to the right without compression, but no evidence of the posterior mediastinal extension found at operation.

nerve away from the mediastinum, and posteriorly it was difficult to ascertain its limits. The thymus felt normal. Frozen section histology showed a hamartoma. Two further pieces were taken for biopsy and silver clips were inserted to delineate the tumour. After an uneventful recovery he remains well.
Further histopathology showed a vascular hamartoma consisting of thin-walled, blood-filled spaces with a few lymphocytes. The walls are thickened in places by smooth muscle (Fig. 7) but the appearance is typical of a cavernous haemangioma. In Fig. 8, varying amounts of adipose and fibrous tissue are seen.

It might appear that mediastinoscopy would have provided a diagnosis without resort to splitting the sternum. In view of the vascularity of the tumour, a mediastinoscopy and biopsy would probably have led to an emergency exploration of the mediastinum for bleeding. More thorough preoperative investigation including mediastinal tomography would have defined the extent of this tumour. It was fortunate that the erroneous preoperative diagnosis of a plunging goitre was made and exploration carried out instead of mediastinoscopy.

\section{Discussion}

The presentation of mediastinal tumours may be diverse as shown by this small group of patients, and it is not unusual for a swelling to be found in the mediastinum without symptoms as in two of our cases. In common with sixteen of forty-two cases reviewed by Attar and Cowley (1964) our patient with a haemangioma had no symptoms. The histo-0 logical description of the tissue removed was that of a vascular hamartoma but it can be seen that the appearances in Figs 7 and 8 would equally well fit

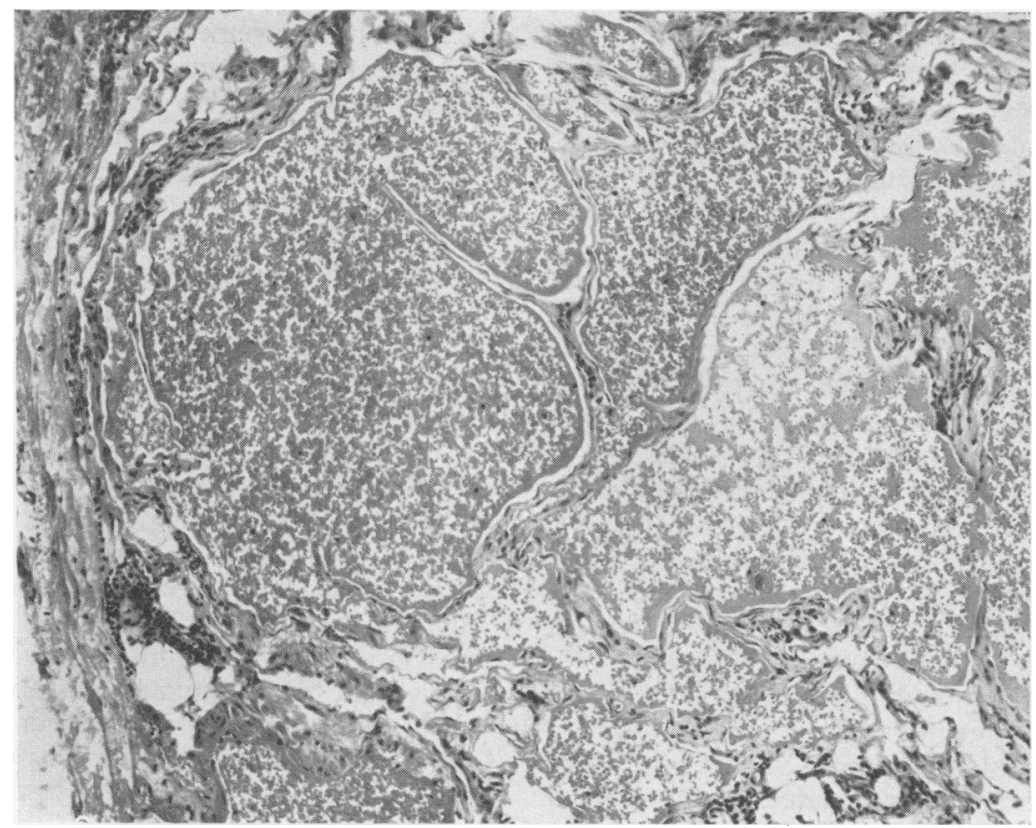

FIG. 7. Case 5. Vascular hamartoma showing large blood filled spaces. ( $\times 104$ magnification $H$. and E.) 


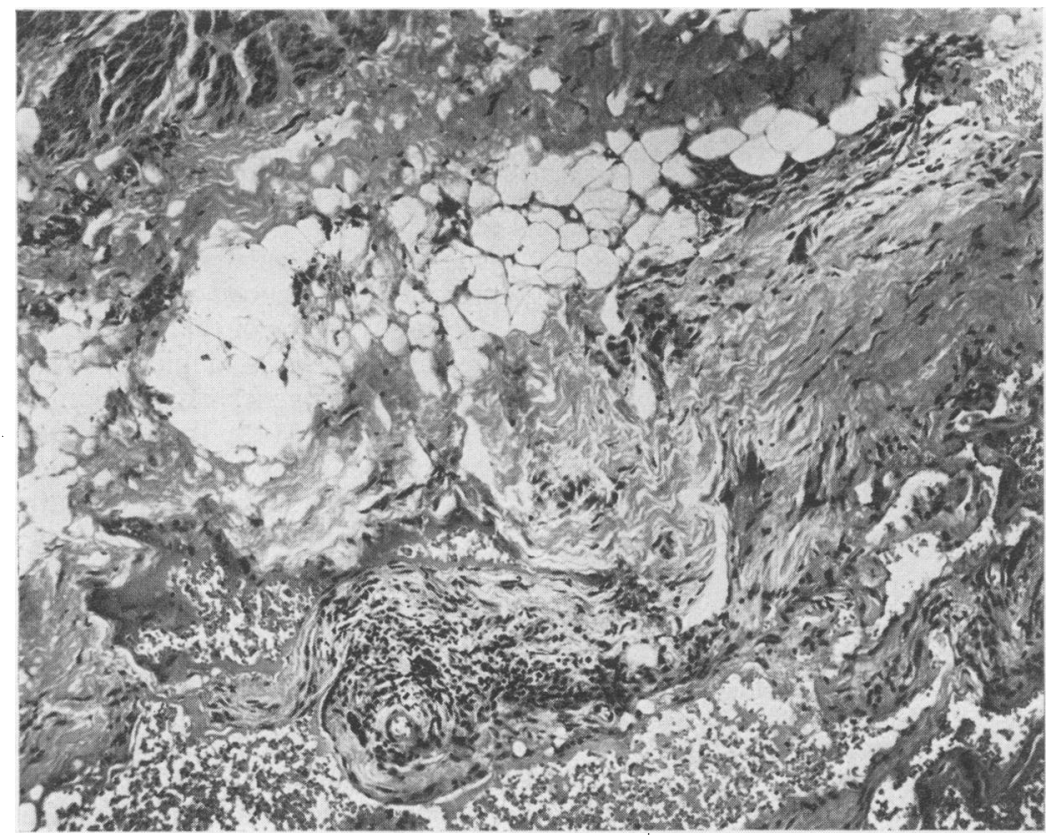

Fig. 8. Case 5. Vascular hamartoma showing areas of fibrous and adipose tissue. $(\times 104$ magnification $H$. and E.)

into the classification of a haemangioma as described by other authors (Adams and Block, 1949; Ellis, Kirklin and Woolmer, 1955; Attar and Cowley, 1964). Although this is a rare mediastinal tumour it is important to consider it in the differential diagnosis for, if a mediastinoscopy and biopsy were to be performed, unforeseen haemorrhage might follow. Exploration in this case was carried out for a mistaken diagnosis of a plunging goitre and more information should have been sought regarding the extent of the tumour preoperatively by tomography.

Once having established the diagnosis by frozen section, excision was contemplated as advocated in previous publications. It was, however, apparent that blood loss would be considerable and that there was involvement of the great veins, phrenic and vagus nerves, and base of the heart. Sacrifice or the risk of injury of these structures was not considered justifiable in a symptom-free patient and it was decided to treat him expectantly. Excision would have been clearly indicated by pressure on the airways, oesophagus or great veins. There is a strong impression from previous publications (Attar and Cowley, 1964; Martin, 1964) that although these congenital tumours can present at any age it is unusual for symptoms to be progressive in older patients. Most of the cases described had no symptoms related to the tumour. This point is not specifically mentioned in previous publications, but it may be an important considera- tion in the management of the asymptomatic case. It is recognized that progressive symptoms may sometimes be due to malignant change. In these cases, exploration is always indicated, but observation may be the best management for those without symptoms.

Another developmental tumour, the teratoma (Case 1), presented in young adult life, originally with a swelling in the root of the neck which was thought to be inflammatory and was incised for drainage. This mode of presentation is documented by Rusby (1964) as common of anterior mediastinal teratoma, and the diagnosis should clearly have been considered in our patient. The presence of a recurrent sinus over the manubrium led to the diagnosis of osteomyelitis, infection resulting from the original incision.

At the time of this late presentation to us with radiological evidence of bony involvement, resection of the manubrium was probably right. If the diagnosis of a teratoma had been considered originally, conservative surgery would have been possible, even after the swelling had been incised for drainage. The most useful investigations, which should have been carried out before the field was obscured by inflammatory reaction, would have been tomography and aspiration of the swelling, possibly followed by mediastinoscopy.

Mediastinoscopy precipitated the demise of a man of 32 years (Case 4) who was subsequently found to 
have a malignant thymoma extensively involving the pericardium. It is tempting to rationalize that this young patient's death was precipitated by incurable disease. Although this may be true, no attempt had been made to delineate the extent of a large superior mediastinal shadow, in a man with a pleural effusion, before mediastinoscopy was performed. The suspicion of an extensive mediastinal tumour could have been aroused had the presence of cardiac tamponade been recognized.

With tamponade in mind, a more extensive exploration than mediastinoscopy would probably have been undertaken to obtain tissue for histological examination. The outcome might have been similar even after open exploration, but it is most unlikely that mediastinoscopy would have been contemplated if the extent of this tumour had been demarcated by preoperative tomography. However, the best that could have been hoped for would have been relief of tamponade so that the radiotherapist could be given an opportunity to provide effective palliation.

Both cases of mediastinal metastasis from a renal carcinoma show interesting features. Mediastinoscopy enabled the diagnosis to be made in one case (Case 2) with a minimum of disturbance, as shown by Carlens (1965) and Pearson and Kergin (1965), and major surgery was avoided. In neither case was it possible to prove that their mediastinal deposits were a result of tertiary spread from pulmonary metastases.

There is no established pathway for lymphatic spread of tumour to the mediastinum from extrathoracic sites (Nohl-Oser, 1972). Even the presence of para-aortic metastasis in Case 2 still defies accepted anatomical pathways to mediastinal lymph glands. It is possible, however, that tumour emboli may have reached these glands through accessory lymphatic channels (Baltaxe and Constable, 1968). It is unlikely that a body wall metastasis such as that in the 7th rib would have embolized to the mediastinum by lymphatic channels. A rational explanation would be that of blood stream embolic spread, although it is a little surprising that no pulmonary deposits were seen during a 2-year survival period in which other metastases were enlarging.

The other case of mediastinal metastasis (Case 3) presumably originated at the time of nephrectomy by haematogenous spread since there was histological proof of venous invasion by tumour. It is most unusual for a 20-year survival to be seen when this has occurred. The longest recorded latent periods from primary tumour to death from metastasis in renal carcinoma are 25 years (Riches, Griffiths and Thackray, 1951) and 20 years (Tandon, Kumar and Haffiz, 1963). These cases emphasize the difficulty of claiming a cure in cancer of the kidney. Our patient has defied the principle that a poor prognosis is associated with invasion of the renal vein although he did have a relatively low grade tumour. Possible regression of metastasis after removal of a primary renal carcinoma, as documented by Smithers (1962), raises the suggestion of hormonal dependence. Why tumour multiplication should suddenly occur 20 years later is not apparent, but the poor response of the tumour in Case 3 to hormone therapy (Bloom, 1964) suggests that it may have been slowly growing for many years. In contrast, Case 2, who presented with metastasis, appears to have received efficient palliation from the combination of cyclophosphamide in small dosage and medroxyprogesterone, for he remained symptom-free until shortly before his death 2 years later. It is almost certainly a coincidence that both cases lived 2 years after presentation with mediastinal deposits.

\section{Conclusions}

From this study of five patients with mediastinal tumour it is possible to emphasize some important points in the management of tumours of the mediastinum.

Firstly, the possibility of the unusual must always be kept in mind and a thorough investigation should include tomography to outline the extent of the swelling. In this field it is suggested that inclined frontal plane tomograms (Greenwell and Wright, 1965) may be particularly useful in offering a further dimension beyond the preoperative investigation of tumours of lung (Peace and Price, 1973) and oesophagus.

Secondly, before undertaking mediastinoscopy it is mandatory to have some idea of the nature and extent of the pathology from a good set of tomograms. This not only indicates the exact site in which to search (mediastinoscopy is futile and dangerous for middle and some posterior mediastinal masses) but may help avoid such disaster as befell our patient with a thymoma (Case 4).

Thirdly, the use of mediastinoscopy in avoiding unnecessary major surgery (Carlens, 1965; Pearson and Kergin, 1965) is confirmed, provided the above precaution is observed.

Fourthly, incision and drainage of swellings in the root of the neck, however inflammatory they may appear, is a hazardous procedure and should be abandoned. It would be preferable to minimize the risk of secondary infection by a simple needle aspiration and then proceed to the appropriate definitive treatment.

Finally, in the management of asymptomatic haemangioma of the mediastinum, the age of the patient may be important, for it appears that progressive enlargement of these benign congenital tumours is unusual in adults. Observation of asymptomatic haemangioma may be the best method of management for adult patients. 


\section{Acknowledgments}

We would like to thank the Consultants concerned for allowing us to study their cases and for helpful criticism. We are grateful to Dr G. A. K. Missen for his helpful assistance with the pathology, also to Mr Fitzpatrick and the Photographic Department, Guy's Hospital, for help in the preparation of the figures and Miss Rosemary Edmonds for typing the manuscript.

\section{References}

Adams, W.E. \& Bloch, R.G. (1949) Hemangioma of the mediastinum, report of a case. Archives of Surgery, 48, 126.

Attar, S. \& Cowley, R.A. (1964) Hemangioma of the mediastinum: collection, review and case report. American Surgeon, 30, 141.

Baltaxe. H.A. \& Constable, W.C. (1968) Mediastinal lymph node visualisation in the absence of intrathoracic disease. Radiology, 90, 94.

Blades, B. (1946) Mediastinal tumours. Report of cases treated at the Army Thoracic Surgery Centers in United States. Annals of Surgery, 123, 749.

Bцоом, H.J.G. (1964) In: Tumours of the Kidney and Ureter, Monographs on Neoplastic Disease Series (Ed. by D. W. Smithers), p. 316. E. S. Livingstone: London.

BoyD, D.P. \& Midell, A.I. (1968) Mediastinal cysts and tumors. An analysis of 96 cases. Surgical Clinics of North America, 48, 493.

Bewer, L.A. \& Dolley, F.S. (1949) Tumours of the mediastinum. American Review of Tuberculosis, 60, 419.

Carlens, E. (1965) Mediastinoscopy. Annals of Otology, Rhinology and Laryngology, 74, 1102.

Ellis, F.H. Kirklin, J.W. \& WoOlner. L.B. (1955) Hemangioma of the mediastinum. Journal of Thoracic Surgery, 30, 181 .
Everson, R.C. \& Cole, W.H. (1959) Spontaneous regression of malignant disease. Journal of the American Medical Association, 142, 1758.

GreenWell, F.P. \& Wright, F.W. (1965) Rotational tomography. Clinical Radiology, 16, 377.

Heuer, G.J. \& ANDRUS, W.DEW. (1940) Surgery of mediastinal tumors. American Journal of Surgery, 50, 146.

Martin, L.W. (1964) Angiomas in infants and children. American Journal of Surgery, 107, 115.

NOHL-OSER, H.C. (1972) An investigation of the anatomy of the lymphatic drainage of the lungs. Annals of the Royal College of Surgeons of England, 51, 157.

Peace, P.K. \& Price, J.L. (1973) Preoperative tomographic assessment of the mediastinum in bronchial carcinoma. Thorax, 28, 367.

Pearson, F.G. \& Kergin, F.G. (1965) Mediastinoscopy: a method of biopsy in the superior mediastinum. Journal of Thoracic and Cardiovascular Surgery, 49, 11.

Riches, E.W., Griffiths, I.H. \& ThackRAY, A.C. (1951) New growths of kidney and ureter (B.A.U.S. series). British Journal of Urology, 23, 297.

Riches, E.W. (1964) In: Tumours of the Kidney and Ureter, Monographs on Neoplastic Disease (Ed. by D. W. Smithers), p. 367. E. S. Livingstone: London.

RuSBY, N.L. (1944) Dermoid cysts and teratomata of the mediastinum. Journal of Thoracic Surgery, 13, 169.

Smithers, D.W. (1962) Spontaneous regression of tumours. Clinical Radiology, 13, 132.

Tandon, P.L., Kumar, M. \& Haffiz, M.A. (1963) Metastases from renal cell carcinoma twenty years after nephrectomy. A case report. British Journal of Urology, 35, 30.

Wychulis, A.R., Payne, W.S., Clagett, O.T. \& Woolner, L.B. (1971) Surgical treatment of mediastinal tumours. 40 year experience. Journal of Thoracic and Cardiovascular Surgery, 62, 379.

Postgraduate Medical Journal (February 1975) 51, 96-99.

\title{
Neonatal listeriosis
}

\author{
S. VARIEND \\ M.B., M.R.C.P., D.C.H.
}

\section{BLUMENTHAL M.B., Ch.B.}

\section{The Jessop Hospital for Women, Sheffield}

\section{Summary}

Three cases of neonatal listeriosis are reported. This local incidence in a busy neonatal unit over a 10-year period would agree with other reports that the condition is rare in the United Kingdom. Two cases had septicaemia and one developed septicaemia and meningitis, contrasting with the previous view that the commonest presentation is with meningitis, and could be due to the greater use of blood cultures in babies suspected of having infection. The mode of delivery differed in each case which allowed certain conclusions to be made regarding pathogenesis of the condition. Thus evidence is presented against fetal infection through an ascending route or while passing through

Correspondence: Dr S. Variend, City Hospital, Nottingham NG5 1PB. an infected birth canal. Maternal bacteraemia with a transplacental spread of infection would seem more likely. The possible use of Gentamicin in the treatment of this condition is discussed and the better prognosis with septicaemia, compared with meningitis, is emphasized.

\section{Introduction}

Listeria monocytogenes is a pleomorphic, motile, Gram-positive rod which shows a characteristic tumbling movement at $25^{\circ} \mathrm{C}$, growth at low temperature, $\beta$-haemolysis on blood agar and an ability to ferment certain sugars. There are four recognized serotypes, of which types 1 and 4 are most commonly encountered in Britain (Public Health Laboratory Service, 1969). 